\title{
A coinfecção tuberculose/HIV com enfoque no cuidado e na qualidade de vida
}

\author{
Tuberculosis/HIV coinfection focused on care and quality of life \\ Coinfección tuberculosis/VIH con enfoque en el cuidado y en la calidad de vida \\ Marcos Vinícius de Freitas Carvalho ${ }^{1}$ (1) https://orcid.org/0000-0003-4633-413X \\ Alexandra Rodrigues dos Santos Silva ${ }^{1}$ i nttps://orcid.org/0000-0002-0621-8209 \\ Mônica Taminato ${ }^{1}$ @ https://orcid.org/0000-0003-4075-2496 \\ Maria Rita Bertolozzi ${ }^{2}$ i nttps://orcid.org/0000-0002-5009-5285 \\ Hugo Fernandes ${ }^{1}$ ib https://orcid.org/0000-0003-2380-2914 \\ Sumire Sakabe ${ }^{3}$ ic https://orcid.org/0000-0002-9054-2844 \\ Paula Hino' ${ }^{1}$ ic https://orcid.org/0000-0002-1408-196x
}

Como citar:

Carvalho MV, Silva AR, Taminato M, Bertolozzi $M R$, Fernandes $H$, Sakabe S, et al. A coinfecção tuberculose/HIV com enfoque no cuidado e na qualidade de vida. Acta Paul Enferm. 2022;35:APE02811.

DOI

http://dx.doi.org/10.37689/acta-ape/2022A002811

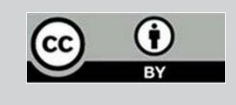

Descritores

Coinfecçãa; Qualidade de vida; HIV; Tuberculose

Keywords

Coinfection; Quality of life; HIV; Tuberculosis

Descriptores

Coinfección; Calidad de vida; VHH; Tuberculosis

Submetido 3 de Outubro de 2019

Aceito

25 de Março de 2021

Autor correspondente Marcos Vinícius de Freitas Carvalho E-mail: mvcarvalho.carvalho@gmail.com

Editor Associado (Avaliação pelos pares): Denise Myuki Kusahara

(https:///rcid org/0000-0002-9498-0868 Escola Paulista de Enfermagem, Universidade Federal de São Paulo, São Paulo, SP, Brasil

\section{Resumo}

Objetivo: Descrever e analisar as percepções de pessoas que vivenciam a coinfecção tuberculose/ vírus da imunodeficiência humana, quanto à qualidade de vida e ao cuidado em saúde.

Métodos: Estudo exploratório, descritivo, com abordagem qualitativa, realizado com dez pessoas que vivenciavam a coinfecção e que recebiam atendimento em um centro de referência do município de São Paulo. Para a coleta de dados, foi utilizado um questionário semiestruturado, composto por questões fechadas e questões norteadoras. A análise dos depoimentos baseou-se na teoria da determinação social do processo saúde-doença.

Resultados: Os participantes apontaram que as condições precárias de vida interferiam na qualidade de vida e referiram satisfação em relação ao cuidado ofertado e com a rede de atenção à saúde. Vivenciar a coinfecção tuberculose/vírus da imunodeficiência humana acarretou sofrimento, isolamento social e estigma, o que pode contribuir para ideação suicida e diminuição da qualidade de vida. Na percepção dos participantes, os profissionais de saúde contribuem para a manutenção da qualidade de vida, por meio do estabelecimento de vínculo e atenção humanizada.

Conclusão: Intervenções voltadas à redução das desigualdades sociais, que apoiem a diminuição de estigma e do preconceito e que incrementem a interação humanizada nos serviços de saúde, de forma a atender às necessidades de saúde dos usuários podem repercutir positivamente na percepção sobre a qualidade de vida e o cuidado em saúde daqueles que vivenciam a coinfecção tuberculose/vírus da imunodeficiência humana.

\section{Abstract}

Objective: To identify the prevalence and thirst intensity in children in the immediate postoperative period and its associated factors.

Methods: This is a cross-sectional and analytical study. The sample consisted of 78 children aged four to twelve years in the post-anesthesia care unit in the immediate postoperative period. Thirst presence, as well as its attributes and signs, were identified by questioning by the researcher and/or self-report of children and their caregivers. Thirst intensity was measured using the face scale. The outcome variables were thirst presence and intensity. Prevalence ratio was calculated by Poisson regression, with robust variance.

Results: The prevalence of thirst was $88.5 \%$, with $39.7 \%$ reporting thirst in the postoperative period and $48.7 \%$ since the preoperative period. As for the intensity, $20.5 \%$ reported strong thirst and $37.2 \%$ intense thirst. Additionally, more than half of the children (59\%) reported it spontaneously. The factors associated with greater thirst intensity were: female sex ( $P R=1.27)$; spontaneous complaint $(P R=1.29)$; reporting feeling of

'Escola Paulista de Enfermagem, Universidade Federal de São Paulo, São Paulo, SP, Brasil.

2Escola Enfermagem, Universidade de São Paulo, São Paulo, SP, Brasil.

${ }^{3}$ Centro de Referência e Treinamento DST/Aids-SP, São Paulo, SP, Brasil.

Conflitos de interesse: Embora Taminato M e Hino P sejam Editoras Associadas da Acta Paulista de Enfermagem, ambas não participaram do processo de avaliação pelos pares do referido artigo. 
dry mouth ( $P R=1.93)$ and thick saliva ( $P R=1.43)$; age was inversely associated with thirst intensity, i.e., the younger the age, the greater the thirst intensity (beta $=-0.053 ; p=0.01$ ).

Conclusion: Thirst in surgical children has a high prevalence and intensity. Children are able to identify the signs related to thirst and spontaneously reports it. Sex, spontaneous complaints, age, dry mouth and thick saliva were associated with intensity. These results signal the need for intentional interventions to reduce child thirst in clinical practice.

\section{Resumen}

Objetivo: Describir y analizar las percepciones de personas que presentan la coinfección tuberculosis/virus de la inmunodeficiencia humana con relación a la calidad de vida y al cuidado de la salud.

Métodos: Estudio exploratorio, descriptivo, con enfoque cualitativo realizado con diez personas que presentaron la coinfección y que recibían atención en un centro de referencia del municipio de São Paulo. Para la recopilación de datos se utilizó un cuestionario semiestructurado, compuesto por preguntas cerradas y preguntas orientadoras. El análisis de los relatos se basó en la teoría de la determinación social del proceso salud-enfermedad.

Resultados: Los participantes señalaron que las condiciones precarias de vida interferían en la calidad de vida y relataron satisfacción con relación al cuidado ofrecido y a la red de atención en salud. Tener la coinfección tuberculosis/virus de la inmunodeficiencia humana conlleva sufrimiento, aislamiento social y estigma, lo que puede contribuir con ideación suicida y reducción de la calidad de vida. Bajo la percepción de los participantes, los profesionales de la salud contribuyen para mantener la calidad de vida, mediante el establecimiento de vínculos y atención humanizada.

Conclusión: Intervenciones orientadas a la reducción de las desigualdades sociales, que apoyen la disminución del estigma y los prejuicios y que aumenten la interacción humanizada en los servicios de salud, a fin de atender las necesidades de salud de los usuarios, pueden repercutir positivamente en la percepción sobre la calidad de vida y el cuidado de la salud de aquellas personas que padecen la coinfección tuberculosis/virus de la inmunodeficiencia humana.

\section{Introdução}

A infecção pelo vírus da imunodeficiência humana (HIV) é um dos principais fatores de risco para o desenvolvimento da tuberculose (TB), a qual continua sendo um dos principais problemas de saúde e causa de morte em todo o mundo. ${ }^{(1,2)}$ De acordo com o Relatório Global de Controle da Tuberculose, o risco de um indivíduo infectado pelo HIV desenvolver a doença, é 28 vezes maior quando comparado à população geral. ${ }^{(2)}$

Em 2019, 10 milhóes de pessoas adoeceram com TB no mundo, sendo que $8,2 \%$ viviam com HIV/aids (PVHA). ${ }^{(1)}$ No Brasil, foram notificados 73.864 casos novos de TB em 2019, o que representa um coeficiente de incidência de $35 \mathrm{ca}$ sos/100.000 habitantes. Do total de casos, 76,1\% realizaram a sorologia para o HIV e 8,4\% testaram positivo. Dentre as pessoas com a coinfecção TB/ HIV, apenas $47,5 \%$ realizavam a terapia antirretroviral (TARV). ${ }^{(3)}$

Com a introdução da política de acesso universal e gratuito à TARV, a partir de 1996, a aids passou a ser caracterizada como uma doença crônica. Nesse sentido, a avaliação da qualidade de vida (QV) é considerada uma medida essencial para propor açóes necessárias para a assistência a essas pessoas. ${ }^{(4,5)}$

Um estudo realizado no interior de São Paulo, com 57 pessoas que vivenciavam a coinfecção TB/
HIV, evidenciou que elas se percebiam frágeis, devido às manifestaçóes clínicas relacionadas à associação das doenças, entre as quais, o emagrecimento e a tosse, com repercussóes na rotina e nos relacionamentos sociais. Destaca-se que a falta de suporte financeiro, somado às dificuldades de saúde repercutiram negativamente na QV. A QV foi resultado da interação entre possíveis suportes sociais, tais como auxílio financeiro, fonte de renda, apoio de amigos e familiares, e sinais e sintomas decorrentes da coinfecção, podendo resultar em melhor ou pior percepção sobre a $\mathrm{QV}$. $^{(6)}$

Pesquisa realizada na Índia, com o objetivo de avaliar e comparar a QV entre pacientes com HIV com e sem TB, demonstrou que pessoas com a coinfecção TB/HIV apresentaram menor escore de QV e maiores chances de manifestarem distúrbios do humor quando comparadas às PVHA que não tinham TB. As pessoas que vivenciavam a coinfecção TB/HIV obtiveram pontuação sugestiva de distúrbios leves do humor, sendo que aquelas com HIV sem TB, em sua maioria, foram classificadas como saudáveis do ponto de vista da saúde mental. ${ }^{(7)}$

Do mesmo modo que o HIV/aids, a TB gera estigma e preconceito, portanto, a pessoa que vivencia a coinfecção enfrenta não apenas consequências físicas das doenças, mas também situações emocionais estressantes e sociais menos favoráveis, que podem repercutir na $\mathrm{QV} .^{(4,8,9)}$ De fato, ambas 
as enfermidades podem causar conflitos internos, dado que a aceitação de um novo estado de comprometimento do processo saúde-doença pode ser plena de dificuldades. ${ }^{(5,6,9)}$

A Organização Mundial da Saúde (OMS) define QV como: “A percepção do individuo de sua posiçâo na vida no contexto da cultura e sistema de valores nos quais ele vive e em relação aos seus objetivos, expectativas, padrôes e preocupaçóes". (10)

A revisão da literatura sobre a temática em questão aponta que a maioria das pesquisas está relacionada às PVHA, e não especificamente à coinfecção TB/HIV. ${ }^{(11-14)}$ Estudos que abordam essa temática se justificam, com vistas a preencher esta lacuna de conhecimento e fornecer elementos que podem contribuir para repensar açóes em saúde que visam melhorar a QV e o cuidado em saúde.

Ademais, a relevância do estudo se refere principalmente à necessidade de desvelar significados e percepçóes do ponto de vista das pessoas que vivenciam a coinfecção TB/HIV, o que pode ser alcançado ao oportunizar a vocalização desse grupo. Destaca-se que foram encontrados apenas três estudos qualitativos sobre o tema. ${ }^{(5,15,16)}$

Em vista do exposto, o presente estudo teve como objetivo descrever e analisar as percepçóes de pessoas que vivenciam a coinfecçáo TB/HIV, no que diz respeito à qualidade de $\mathrm{QV}$ e ao cuidado em saúde.

\section{Métodos}

Trata-se de um estudo descritivo com abordagem qualitativa sobre a QV e o cuidado em saúde, segundo as percepçóes de pessoas que vivenciam a coinfecção TB/HIV. O cenário do estudo foi um Centro de Referência e Treinamento em aids (CRT) do município de São Paulo. Os critérios de inclusão foram: pessoas com idade igual ou superior a 18 anos, independentemente do sexo, que apresentaram sorologia reagente para o HIV, tendo desenvolvido ou não a síndrome, que estavam realizando o tratamento da TB e TARV há pelo menos um mês e que apresentavam condiçóes físicas e cognitivas para responder ao questionário. $\mathrm{O}$ critério de exclusão foi estar privado de liberdade no momento da coleta de dados.

Para a coleta de dados, foi utilizado um instrumento semiestruturado, composto por questóes elaboradas exclusivamente para este estudo, sobre o perfil sociodemográfico e de saúde, e pelas seguintes questóes norteadoras: "1) Relate uma situação marcante que você viveu desde que teve o diagnóstico de TB e HIV; 2) O tratamento da TB e a TARV fez com que aparecessem necessidades que não tinha antes?; 3) Como você avalia sua qualidade de vida?; 4) O serviço de saúde te ajuda no enfrentamento das suas necessidades?". As questóes permitiram aos entrevistados discorrer livremente sobre o tema em questão. Com a finalidade de verificar a clareza das questóes e realizar os ajustes necessários, foi realizado um estudo piloto, com quatro pessoas que vivenciavam a coinfecção TB/HIV, e que náo foram incluídas no estudo.

As pessoas que vivenciavam a coinfecção $\mathrm{TB} /$ HIV foram convidadas a participar da pesquisa por ocasião do comparecimento para consulta médica ou para a retirada da medicação. As entrevistas foram realizadas entre abril e agosto de 2019 , por um dos autores do artigo, que foi previamente capacitado para a realizaçáo da entrevista. A coleta de dados ocorreu em uma sala reservada nas dependências da Instituição, a fim de garantir a privacidade e a qualidade das informaçôes. As entrevistas duraram em média 25 minutos e foram gravadas por meio de gravador digital de áudio, para proporcionar maior autenticidade na compreensão das percepçóes dos participantes. Posteriormente, seu conteúdo foi transcrito pelo próprio entrevistador.

Os depoimentos foram identificados por uma letra seguida de um número arábico para garantir o anonimato dos participantes. A etapa seguinte envolveu a leitura em profundidade dos depoimentos, com vistas à apreensão de significados sobre a QV e o cuidado em saúde prestado às pessoas que vivenciam a coinfecção TB/HIV.

Para a análise do material empírico, foi utilizado o método de análise de discurso, que permitiu a depreensão de expressóes da vida real, contendo as visóes de mundo das pessoas, a respeito dos elementos da realidade objetiva que se materializam 
nas representaçôes. ${ }^{(17)} \mathrm{A}$ análise dos depoimentos foi realizada à luz da Teoria da Determinação Social do Processo Saúde-Doença.

Em se tratando de pesquisa que envolve seres humanos, o projeto atende às normas da Resolução no 466/2012 e foi aprovado pelo Comitê de Ética (parecer número: 2.906.733) e pelo Comitê de Ética em Pesquisa do referido serviço de saúde onde ocorreram as entrevistas (parecer número: 3.267.922) (CAAE: 91820618.0.3001.5375).

\section{Resultados}

As entrevistas seguiram o critério de saturação das informaçôes, tendo participado dez pessoas que vivenciavam a coinfecção TB/HIV. As tabelas 1 e 2 apresentam algumas características sociodemográficas e de saúde dos entrevistados.

A maioria dos participantes era do sexo biológico masculino $(n=9)$, sendo que destes, duas pessoas se declararam mulheres trans. Metade dos entrevistados referiu estar à procura de emprego, dois declararam estar afastados de suas atividades laborais em decorrência da TB e de outras doenças oportunistas, e três se aposentaram por invalidez devido à alguma incapacidade incurável relacionada ao HIV. Em relação ao HIV, a maioria acreditava ter contraído o vírus por via sexual $(\mathrm{n}=9)$, tinha conhecimento do seu estado sorológico há mais de dez anos $(\mathrm{n}=7)$, seis referiram carga viral inferior a 50 cópias/ $\mathrm{ml}$ e metade dos participantes realizava a TARV há mais de 360 dias. Quanto à TB, foi predominante a forma pulmonar e sete estavam em tratamento por período de 31 a 90 dias. Em relação à análise dos depoimentos, emergiram temáticas que foram agrupadas em quatro categorias (Figura 1).

A análise em profundidade dos depoimentos possibilitou conhecer a percepção das pessoas que apresentavam a coinfecção TB/HIV, no que diz respeito à QV e ao cuidado em saúde. Em relação à categoria "O impacto da Coinfecção", a maioria dos entrevistados referiu ideação suicida em decorrência do HIV. Um dos entrevistados relatou que tentou suicídio por mais de uma vez, decorrente do sofrimento causado por seu estado sorológico. $\mathrm{O}$
Tabela 1. Perfil sociodemográfico dos participantes do estudo. Centro de Referência e Tratamento em Aids

\begin{tabular}{|c|c|}
\hline Variáveis & Frequência absoluta \\
\hline \multicolumn{2}{|l|}{ Gênero } \\
\hline Masculino & 7 \\
\hline Feminino & 1 \\
\hline Transexual & 2 \\
\hline \multicolumn{2}{|l|}{ Orientação sexual } \\
\hline Homossexual & 5 \\
\hline Heterossexual & 4 \\
\hline Bissexual & 1 \\
\hline \multicolumn{2}{|l|}{ Faixa etária (anos) } \\
\hline 18 a 29 & 3 \\
\hline 30 a 39 & 2 \\
\hline 40 a 49 & 3 \\
\hline 50 a 59 & 2 \\
\hline \multicolumn{2}{|l|}{ Cor da pele } \\
\hline Branca & 5 \\
\hline Parda & 5 \\
\hline \multicolumn{2}{|l|}{ Religião } \\
\hline Não possui & 4 \\
\hline Budista & 1 \\
\hline Católico & 4 \\
\hline Evangélico & 1 \\
\hline \multicolumn{2}{|l|}{ Escolaridade (anos) } \\
\hline $1 \mathrm{a} 4$ & 1 \\
\hline 5 a 8 & 1 \\
\hline 9 a 12 & 7 \\
\hline 13 a 16 & 1 \\
\hline \multicolumn{2}{|l|}{ Estado civil } \\
\hline Solteiro & 8 \\
\hline Casado/união estável & 2 \\
\hline \multicolumn{2}{|l|}{ Ocupação } \\
\hline Aposentado & 3 \\
\hline Desempregado & 5 \\
\hline Profissional do sexo & 1 \\
\hline Comércio & 1 \\
\hline \multicolumn{2}{|l|}{ Renda familiar (reais) } \\
\hline Sem renda & 2 \\
\hline$\leq \mathrm{a} 1 \mathrm{SM}^{\star}$ & 1 \\
\hline Entre 2 e $3 \mathrm{SM}$ & 3 \\
\hline$>3 \mathrm{SM}$ & 4 \\
\hline
\end{tabular}

SM - salário-mínimo

adoecimento pela TB foi mencionado como situação desmotivadora, pois alguns entrevistados não acreditavam no sucesso do tratamento. Segundo os entrevistados, a desmotivação e a ideação suicida constante influenciam negativamente na $\mathrm{QV}$.

"A principio eu tinha muito (humor deprimido), eu tinha vontade, claro né, acabei tentando suicidio, não foi uma vez só não...”. E8

A maioria dos entrevistados $(n=6)$ teve o diagnóstico de sorologia positiva para o HIV durante um relacionamento estável, sendo que alguns vi- 
Tabela 2. Perfil de saúde-doença dos participantes do estudo. Centro de Referência e Tratamento em Aids

\begin{tabular}{ll}
\hline Variáveis & Frequência absoluta \\
\hline Forma de exposição & 9 \\
Sexual & 1 \\
$\quad$ Não sabe & \\
Tempo de diagnóstico do HIV (anos) & 2 \\
$\quad<1$ & 1 \\
6 a 9 & 7 \\
$>10$ & \\
Carga viral (cópias/ml) & 6 \\
$\quad<50 /$ indetectável & 4 \\
50 a 20.000 & \\
Células TCD4 & 5 \\
$\quad<200$ & 3 \\
200 a 350 & 2 \\
$>350$ & \\
Uso da TARV (dias) & \\
31 a 90 & 1 \\
91 a 360 & 4 \\
$>360$ & 5 \\
Forma clínica da TB & \\
Pulmonar & \\
Pulmonar + Extrapulmonar & 8 \\
Tratamento da TB (dias) & \\
31 a 90 & \\
91 a 360 & 7 \\
\hline
\end{tabular}

\begin{tabular}{|c|c|c|c|}
\hline $\begin{array}{l}0 \text { impacto da } \\
\text { coinfecção }\end{array}$ & $\begin{array}{l}\text { A vida após a } \\
\text { coinfecção }\end{array}$ & Qualidade de Vida & $\begin{array}{l}0 \text { cuidado no } \\
\text { serviço de saúde }\end{array}$ \\
\hline $\begin{array}{l}\text { Descoberta dos } \\
\text { diagnósticos; } \\
\text { Ideação suicida; } \\
\text { Desmotivação; } \\
\text { Negação dos } \\
\text { diagnósticos. }\end{array}$ & $\begin{array}{l}\text { Sigilo; } \\
\text { Isolamento social/ } \\
\text { sofrimento; } \\
\text { Auto-estigma; } \\
\text { Resposabilização } \\
\text { sobre a transmissão } \\
\text { das doenças; } \\
\text { Dificuldade de } \\
\text { relacionamento; } \\
\text { Debilidade física. }\end{array}$ & $\begin{array}{l}\text { Efeitos colaterais dos } \\
\text { tratamentos; } \\
\text { Determinantes } \\
\text { sociais de saúde; } \\
\text { Apoio familiar e de } \\
\text { amigos. }\end{array}$ & $\begin{array}{l}\text { Organização do } \\
\text { serviço; } \\
\text { Postura profissional; } \\
\text { Vulnerabilidade } \\
\text { ao abandono dos } \\
\text { tratamentos; } \\
\text { Apoio social. }\end{array}$ \\
\hline
\end{tabular}

Figura 1. Categorias de análise e seus elementos constitutivos

venciavam um longo período de monogamia, contribuindo para uma percepção negativa sobre o processo saúde-doença, pois, segundo eles, a rotina imposta pelos tratamentos acarretava em lembrança constante de traiçóes realizadas por seus antigos parceiros, com impacto negativo na QV. Vivenciar o óbito de parceiros e amigos, decorrentes de complicações do HIV, também interferiu na concepção negativa sobre a enfermidade, com repercussóes na $\mathrm{QV}$, ao restringir suas redes sociais de suporte. Ressalta-se, que foi comum, a não aceitação do diagnóstico do HIV por um longo período, havendo inclusive, a continuidade das relaçóes sexuais casuais sem uso do preservativo. Ainda que parado- xal, segundo os entrevistados, negar os diagnósticos possibilitou melhorar a percepção em relação à QV, pois acreditavam que sofreriam menos com a realidade vivenciada.

A categoria referente à "A vida após a Coinfecção" incluiu representaçóes sobre constrangimento e decepção que sentiram de si mesmos por possuírem tanto a TB quando o HIV, e medo da discriminação e do preconceito, que determinou isolamento social imposto por eles próprios a fim de se protegerem. Nessa linha, observou-se relatos de desdobramentos negativos sobre a QV. O sigilo do diagnóstico foi expresso como estratégia de enfrentamento para essa situação, possibilitando melhor percepção sobre a QV.

Outro aspecto relevante refere-se à responsabilização pela transmissáo do HIV, visto que a maioria se preocupava com a proteção do parceiro(a), tendendo ao comportamento sexual de abstinência, enquanto por outro lado, verificou-se aqueles que continuaram mantendo relaçóes sexuais desprotegidas. Aqueles que optaram por se responsabilizar pela transmissão do vírus, relataram dificuldade no estabelecimento de relaçóes amorosas, resultando em sentimento de solidão, com influências negativas na QV. Verificou-se que situaçóes de isolamento social, de auto discriminação e de dificuldade de estabelecer relacionamentos amorosos resultaram em sofrimento e em possível diminuição da QV, sendo necessário acompanhamento psicológico para conseguirem conviver com tal angústia.

“...me isolei por um ano, não encontrei ninguém, nâo queria olhar ninguém no olho, ou por preconceito meu em relação à doença, ou por preconceito dos outros, eu acho que o mais difícil é: - Por que um cara casado está com isso? Foi ao baile? Não, peguei em casa”. E9

Houve menção que a associação do HIV à TB causou debilidade física significativa, a ponto de impedir as atividades do cotidiano, também com impacto negativo na QV.

A categoria referente à "Qualidade de Vida” reuniu representaçóes que evidenciaram o conhecimento da sorologia positiva na fase adulta e dificuldade de adesão aos tratamentos devido aos efeitos colaterais, com 
impacto na percepção sobre a QV. Por outro lado, os participantes cuja descoberta do estado sorológico ocorreu na adolescência, relataram que náo se recordavam como era a QV antes do HIV, pois apenas se lembravam de suas vidas após o diagnóstico, o que parece revelar o impacto que a enfermidade causa em suas vidas.

Foi evidenciado que vivenciar a TB juntamente com o HIV pode ter contribuído para a diminuição da QV. Outros elementos que podem ter contribuído para a diminuição da QV foram: moradia insalubre, situação de violência física e/ou sexual, repressão religiosa e familiar por conta da orientação sexual, exposição e humilhação, tratamento do Sarcoma de Kaposi, privação de liberdade, preconceito por ser transexual ou pela orientação sexual. Também foram relatadas dependência de álcool e outras drogas, como cocaína e crack, e descoberta do estado sorológico do parceiro.

Os participantes do estudo referiram não ser possível dissociar os fatores sociais dos individuais para analisar como a TB e o HIV podem ter influenciado a QV. Segundo eles, a interação entre condicionantes sociais das mais variadas ordens, além da representação sobre os mesmos, ou seja, a forma como a pessoa expressa a sua subjetividade, influenciam a vivência da infecção TB/HIV, com resultados na percepção sobre a $\mathrm{QV}$, conforme pode ser verificado no excerto a seguir:

"Ter HIV não é só uma doença crônica, vai além disso, tenho repressão religiosa, sem proteção da familia, exposto ao público, hiperdesenvolvido sexualmente por conta do abuso, vítima de espancamento, então são questóes que trago comigo toda vez que tomo um comprimido". E2

A negligência em relação à saúde que alguns dos entrevistados mencionaram, esteve associada às experiências traumáticas que, segundo eles, suscitaram sofrimento, angústia e baixa autoestima, o que dificultou a busca para o cuidado em saúde, e refletiu na QV.

Por outro lado, os entrevistados referiram que o apoio familiar e dos amigos foi fundamental para a aceitação dos diagnósticos da TB e do HIV, assim como para se sentirem motivados na continuidade dos tratamentos, com repercussão positiva na $\mathrm{QV}$.
A categoria "O Cuidado no Serviço de Saúde" incluiu representaçóes que evidenciaram que os entrevistados ressaltaram a importância da organização adequada do processo de trabalho para atender às necessidades de saúde e demandas desse segmento populacional, o que gerou satisfação e que, segundo eles, era fundamental para a manutenção da QV. Os entrevistados destacaram como positiva o modo como eram atendidos pelos profissionais de saúde do serviço.

"Já passei por vários lugares, O CRT é um paraiso... você vê a atenção do corpo de enfermagem, sempre alegres, te abraçam, é um calor bumano muito grande, aqui tudo funciona... se você está com um problema, todos focam em você e vão dar um jeito de resolver, então, isso você não vê em lugar nenhum, nem em particular". E4

É importante ressaltar que houve casos de abandono do tratamento tanto da TB quanto do HIV, sendo que alguns se recusaram a aceitar o novo estado de saúde. No caso do abandono do tratamento da $\mathrm{TB}$, foi associado à desesperança em relação ao tratamento. Também houve relatos sobre a presença de doenças oportunistas e recidiva da TB.

Alguns participantes referiram não possuir condiçóes financeiras para dar continuidade aos tratamentos, sendo fundamental a oferta de medidas de apoio social, não apenas por meio de auxílio financeiro, mas também como apoio da família e de amigos, simultaneamente ao atendimento humanizado no serviço de saúde.

\section{Discussão}

O conhecimento da percepçáo sobre a QV e o cuidado em saúde, na perspectiva de pessoas que vivenciam a coinfecção TB/HIV, pode auxiliar na proposição e implementação de açôes de saúde voltadas a este grupo específico, além de possibilitar compreender suas necessidades de saúde.

A maioria dos entrevistados eram mulheres transexuais e homens que mantinham relaçóes sexuais com outros homens (HSH), referiram contaminação pelo HIV por via sexual, e descoberta do estado sorológico enquanto viviam em relação estável, o 
que ressalta a necessidade de políticas públicas voltadas a esse grupo. Isso porque, ainda que esforços tenham sido empreendidos em relação à conscientização a respeito das formas de transmissão e do potencial de transmissão do HIV, ainda se verifica vulnerabilidade, sobretudo quando se considera os significados sobre essa questão para a população em geral. Essa interpretação configura a dimensão individual do conceito de vulnerabilidade. ${ }^{(18)}$

As evidências científicas não abordam a relação entre orientação sexual e identidade de gênero das pessoas que vivenciam a coinfecção TB/HIV. Uma Revisão Sistemática sobre o perfil sociodemográfico dessa população indicou associação com heterossexualidade, porém os autores questionaram esse achado e explicitaram que a maioria das pesquisas utilizou dados do Sistema de Informação de Agravos de Notificação (SINAN), que não possui campo referente a tais informaçóes. ${ }^{(19)}$

O perfil sociodemográfico dos entrevistados demonstrou condiçóes sociais que evidenciam vulnerabilidade social, o que requer políticas públicas que diminuam as desigualdades sociais e que proporcionem melhores condiçóes de vida e de trabalho. Também se verifica a necessidade de atuação dos serviços de saúde em relação ao acompanhamento dessa população, pois a maioria tinha conhecimento do diagnóstico há mais de dez anos, referiu baixa carga viral, mas desenvolveu a $\mathrm{TB}$, sendo que, em alguns casos, a manifestação da infecção oportunista esteve relacionada à não aceitação da infecção pelo HIV. Esse fato demonstra a necessidade de a equipe de enfermagem fortalecer as açóes de busca ativa de sintomáticos respiratórios, a fim de evitar a emergência de doenças oportunistas e recidiva da TB nesse segmento, com repercussão sobre a QV.

Estudo realizado em um município do interior de São Paulo sobre a adesão à TARV demonstrou que pessoas com maior idade, maior tempo de diagnóstico do HIV, menor carga viral e maior número de células TCD4 apresentaram melhor adesão à terapêutica. ${ }^{(20)}$ Esses achados corroboram com a presente pesquisa, que mesmo portando tais condiçóes, apontaram baixa QV. Outro estudo, realizado em Sáo Paulo, sobre as dificuldades no manejo do $\mathrm{HIV}$, demonstrou que a $\mathrm{QV}$ vai além da doença, pois envolve aspectos sociais que impedem o desen- volvimento pessoal, profissional e afetivo, com destaque para o preconceito vivenciado por quem tem a infecção. ${ }^{(21)}$

Também foi relevante que todos os entrevistados referiram que suas atividades laborais foram afetadas pela vivência de uma das infecçôes, seja a TB ou o HIV, demonstrando como o adoecimento pode interferir na renda dessas pessoas e famílias e em consequência, comprometer a QV. Na literatura não foram encontrados estudos que avaliaram o impacto da coinfecção TB/HIV sobre a inserção no mercado de trabalho.

Os entrevistados referiram que se sentiam acolhidos pela equipe de saúde, ao relatar que os profissionais se importavam com suas histórias de vida, e, muitas vezes, promovendo a atenção que não esperavam, o que era fundamental para a manutenção da QV. Esses achados corroboraram estudos realizados em Minas Gerais e no município de Ribeirão Preto. ${ }^{(20,22)}$

A Política Nacional de Humanização (PNH) tem o intuito de reforçar a importância da ambiência na assistência à saúde, entendendo-se que o acompanhamento nos serviços deve resultar em satisfação dos usuários. ${ }^{(23)}$ Estudo realizado no interior de São Paulo, sobre a adesão ao TARV, reforça a importância de fortalecer estratégias multidisciplinares, integrais e multidimensionais, a fim de promover o envolvimento da pessoa em seus tratamentos. ${ }^{(20)}$

$\mathrm{Na}$ presente investigação foram frequentes os relatos de que o auto-estigma e o medo da discriminação, foram responsáveis pelo isolamento social, o que corrobora resultados de um estudo realizado em um município paulista. Neste, maiores pontuaçóes de QV relacionaram-se ao maior apoio social e emocional. ${ }^{(6)}$

Neste sentido, aponta-se a necessidade da participação do enfermeiro, que pode ajudar a aproximar a rede de apoio à pessoa que vivencia as doenças, constituída por familiares e amigos, os quais foram tidos como essenciais pelos entrevistados, o que pode contribuir para melhorar a concretização e a percepção sobre a QV.

Os entrevistados compreendiam que as condiçóes de vida e trabalho estavam relacionadas à situação de saúde, seja pela maior ou menor suscetibilidade de adoecer. Quando questionados sobre a QV, foram apontadas questóes relacionadas à pobreza, 
violência, preconceito, isolamento, dificuldades de relacionamento, o que vai de encontro aos resultados de um estudo realizado em um município do interior paulista, que evidenciou associação entre desemprego, falta de suporte social, isolamento social e efeitos colaterais das medicaçóes para TB e HIV à dificuldade de adesão ao tratamento e à diminuição da QV. ${ }^{(20)}$

Os depoimentos evidenciaram algumas experiências que se repetiram, tais como: negação do diagnóstico, isolamento social e soma dos efeitos colaterais do tratamento da TB e da TARV. A experiência de vivenciar a coinfecção TB/HIV revelou sofrimento que, muitos apontaram ser resultado das situaçóes de violência e exclusão a que foram expostos durante a vida, resultando em percepção negativa sobre a qualidade de suas vidas.

Também foi relatado que vivenciar a coinfecção TB/HIV não foi a questão central que fez repercutir na diminuição da QV, e sim, os determinantes sociais de saúde que se somam a esse momento.

De fato, segundo os entrevistados, a QV, resultado da vivência da coinfecção TB/HIV, derivou de um combinado que envolvia diversos fatores sociais e de saúde que impactam na percepção sobre a QV. A sintomatologia, os efeitos colaterais das medicaçóes, o preconceito social decorrente de ambas as enfermidades, ao mesmo tempo em que aspectos relativos às condiçôes de vida e de trabalho, como falta de moradia, desemprego, além de outros, que podem ser apontados como decorrentes da organização da sociedade, que produz desigualdades e que incidem no processo saúde-doença, como a dependência química, ou ainda, elementos que evidenciam concepçóes ideológicas equivocadas, como, o preconceito advindo da orientação sexual ou da identidade de gênero foram, segundo os participantes, elementos individuais que causaram impacto na QV.

Os depoimentos corresponderam à definição de QV da OMS, que transcende a saúde física, ao também integrar aspectos emocionais e sociais. ${ }^{(10)}$ Estudos realizados na Etiópia, Brasil e Nigéria demonstraram que a QV sofreu consequências negativas devido à associação entre ambas as infecçôes. ${ }^{(4,8,9,24)}$ De fato, a pobreza, o sofrimento decorrente do enfrentamento das precárias condiçóes de vida e de trabalho, e a consequente baixa autoestima resultaram em menor $\mathrm{QV}$ em pessoas que vivenciam a coinfecção TB/HIV, conforme relatos do presente estudo e também evidenciados em estudos realizados na Etiópia, Tailândia e África do Sul. ${ }^{(4,8,25,26)}$ Outros estudos também confirmaram as percepções dos entrevistados, ao apontarem que ter fonte de renda, maior grau de escolaridade, e apoio familiar e social contribuem para a manutenção da $\mathrm{QV} .^{(6,8,25,26)}$

É importante afirmar que as variáveis relacionadas às condiçóes sociais e que a OMS reconhece como determinantes sociais são inerentemente relacionadas à $\mathrm{QV}$, uma vez que perfazem condiçóes para o aprimoramento, enfrentamento ou desgaste no andar da vida. Entretanto, destaca-se que a análise do objeto do presente estudo, à luz da Determinação Social do Processo Saúde-Doença, requer o entendimento de que a estruturaçáo da sociedade e seu modo de organização determinam específicos processos de reprodução social, ou seja, possibilidades específicas de vivenciar a saúde-doença, em função do diferente pertencimento aos grupos sociais. Assim, o enfrentamento do processo saúde-doença e os desgastes sofridos pelas pessoas que vivenciam a coinfecção são mediados pela especificidade na inserção social.

Considera-se que os achados da presente pesquisa trazem contribuições para a compreensão da forma como pessoas que vivenciam a associação $\mathrm{TB} / \mathrm{HIV}$ percebem sua QV. Como limitaçáo do estudo, considera-se que o conceito de QV é complexo e envolve aspectos que se referem à vivência da enfermidade, à subjetividade, às condiçóes de vida e de trabalho, além das possibilidades de acesso aos serviços de saúde. Tal complexidade pode náo ter sido expressa em sua totalidade, uma vez que o estudo aprende uma parte da totalidade da vivência dos participantes.

\section{Conclusão}

A partir da análise dos depoimentos, observou-se que a organização do serviço de saúde, ao acolher as pessoas que apresentam a coinfecção TB/HIV, além do apoio ao tratamento, que não se restringe à assistência, mas também se refere ao provimento da gratuidade da medicaçáo e de apoio ao seguimento do tratamento, influenciam na QV. Intervençôes em saúde que considerem as condiçóes de vida, de trabalho, as 
vulnerabilidades decorrentes, e a vivência do processo saúde-doença são fundamentais para a melhora da $\mathrm{QV}$, além de açóes de proteção social e intervençóes voltadas à diminuição das desigualdades sociais.

\section{Agradecimentos}

Agradecemos à Fundação de Amparo à Pesquisa do Estado de São Paulo (FAPESP), pela concessão de bolsa de Iniciação Científica.

\section{Colaborações}

\section{Carvalho MVF, Silva ARS, Taminato M, Bertolozzi MR, Fernandes H, Sakabe S, e Hino P colaboraram com a contribuição do estudo, análise e interpre- tação dos dados, redação do artigo, revisão crítica relevante do conteúdo intelectual e aprovação da versão final a ser publicada.}

\section{Referências}

1. World Health Organization (WHO). Global Tuberculosis Control: Who Report. 2020. Geneva: WHO; 2020.

2. World Health Organization (WHO). Global Tuberculosis Control: Who Report. 2015.Geneva: WHO; 2015.

3. Brasil. Ministério da Saúde. Departamento de Doenças de Condições Crônicas e Infecções Sexualmente Transmissiviveis. Tuberculose 2020. Bol Epidemiol. 2020; (no. espec):1-19.

4. Deribew A, Deribe K, Reda AA, Tesfaye M, Hailmichael Y, Maja T, et al. Change in quality of life: a follow up study among patients with HIV infection with and without TB in Ethiopia. BMC Public Health. 2013;13(13):408.

5. Lemos LA, Feijão AR, Gir E, Galvão MT. Quality of life aspects of patients with HIV/tuberculosis co-infection. Acta Paul Enferm. 2012; 25 (Spec Issue 1): 41-7.

6. Neves LA, Castreghinic C, Reis RK, Canini SE, Gir E. Social support and quality of life of people with tuberculosis/HIV. Enfermería Global. 2018;50:11-20.

7. Jha DK, Jha J, Jha AK, Achappa B, Holla R. Quality of life among HIVtuberculosis co-infected patients. Perspect Clin Res. 2019;10(3):125-9.

8. Deribew A, Tesfaye M, Hailmichael Y, Negussu N, Daba S, Wogi A, et al. Tuberculosis and HIV co-infection: its impact on quality of life. Health Qual Life Outcomes. 2009;7(7):105.

9. Neves LA, Canini SR, Reis RK, Santos CB, Gir E. [Aids and tuberculosis: coinfection from the perspective of the quality of life of patients]. Rev Esc Enferm USP. 2012;46(3):704-10.Portuguese.
10. World Health Organization (WHO). Country protocol for developing the WHO quality of life (WHOQOL): HIV/AIDS module. Geneva:WHO; 1997.

11. Melaku T, Mamo G, Chelkeba L, Chanie T. Health-related quality of life among people living with human immunodeficiency virus on highly active antiretroviral therapy in Ethiopia: PROQOL-HIV Based Survey. Patient Relat Outcome Meas. 2020;11:73-86.

12. Valdelamar-Jiménez J, Lins-Kusterer L, de Jesus STG, Netto EM, Brites C. Comparison of three health-related quality of life instruments to evaluate symptoms of depression in HIV patients in Brazil. $\mathrm{J}$ Clin Psychol Med Settings. 2020;27(4):643-50.

13. Jiang $T$, Zhou $X$, Wang $H$, Luo $M$, Pan $X$, Ma $Q$, et al. Psychosocial Factors Associated with Quality of Life in Young Men Who Have Sex with Men Living with HIV/AIDS in Zhejiang, China. Int J Environ Res Public Health. 2019;16(15):2667.

14. Fuster-RuizdeApodaca MJ, Laguía A, Safreed-Harmon K, Lazarus JV, Cenoz S, Del Amo J. Assessing quality of life in people with HIV in Spain: psychometric testing of the Spanish version of WHOQOL-HIVBREF. Health Qual Life Outcomes. 2019;17(1):144.

15. Isaakidis P, Rangan S, Pradhan A, Ladomirska J, Reid T, Kielmann K. 'I cry every day': experiences of patients co-infected with HIV and multidrugresistant tuberculosis. Trop Med Int Health. 2013;18(9):1128-33.

16. Furin J, Isaakidis P, Reid AJ, Kielmann K. 'I'm fed up': experiences of prior anti-tuberculosis treatment in patients with drug-resistant tuberculosis and HIV. Int J Tuberc Lung Dis. 2014;18(12):1479-84.

17. Fiorin JL, Savioli FP. Para entender o texto: leitura e redação. São Paulo: Ática; 1991.

18. Ayres JR, Paiva V, França I Jr, Gravato N, Lacerda R, Della Negra M, et al. Vulnerability, human rights, and comprehensive health care needs of young people living with HIV/AIDS. Am J Public Health. 2006;96(6):1001-6.

19. Bastos SH, Taminato M, Fernandes H, Figueiredo TM, Nichiata LY, Hino P. Perfil Sociodemográfico e de saúde da coinfecção tuberculose/HIV no Brasil: revisão sistemática. Rev Bras Enferm. 2019;72(5):1389-96.

20. Foresto JS, Melo ES, Costa CR, Antonini M, Gir E, Reis RK. Adesão à terapêutica antirretroviral de pessoas vivendo com HIV/aids em um município do interior paulista. Rev Gaúcha Enferm. 2017;38(1):1-7.

21. Jesus GJ, Oliveira LB, Caliari JS, Queiroz AA, Gir E, Reis RK. Dificuldades do viver com HIV/AIDS: entraves na qualidade de vida. Acta Paul Enferm. 2017;30(3):301-7.

22. Freitas MI, Bonolo PF, Miranda WD, Guimarães MD. Interactions and the antiretroviral therapy adherence among people living with HIV/ AIDS. REME Rev Min Enferm. 2017; 21: 1-4.

23. Brasil. Ministério da Saúde. Secretaria de Atenção à Saúde. Núcleo Técnico da Política Nacional de Humanização. Ambiência. 2nd ed. Brasília (DF): Ministério da Saúde; 2010. 32p. [Série B. Textos Básicos de Saúde].

24. Kanu NE, Tobin-West Cl. Health-related quality of life of HIV patients with and without tuberculosis registered in a Tertiary Hospital in Port Harcourt, Nigeria. HIV AIDS Rev. 2018;17(3):210-7.

25. Kittikraisak W, Kingkaew P, Teerawattananon Y, Yothasamut J, Natesuwan S, Manosuthi $W$, et al. Health related quality of life among patients with tuberculosis and HIV in Thailand. PLoS One. 2012;7(1):e29775.

26. Louw J, Peltzer K, Naidoo P, Matseke G, Mchunu G, Tutshana B. Quality of life among tuberculosis (TB), TB retreatment and/or TB-HIV coinfected primary public health care patients in three districts in South Africa. Health Qual Life Outcomes. 2012;10(77):77. 